\title{
The microgravity enhanced polymer-mediated siRNA gene silence by improving cellular uptake
}

\author{
Tongren Yang ${ }^{1}$, Chanchan $\mathrm{Yu}^{1}$, Changrong Wang ${ }^{2}$, Chunhui $\mathbf{L i}^{1}$, \\ Mengjie Zhang ${ }^{1}$, Xiaofan Luo ${ }^{1}$, Yuhua Weng ${ }^{1}$, Anjie Dong ${ }^{2}$, Xiaoqiong $\mathrm{Li}^{1}$, \\ Yulin Deng ${ }^{1}$, Yuanyu Huang ${ }^{1,3 \bowtie}$
}

${ }^{1}$ School of Life Science, Advanced Research Institute of Multidisciplinary Science, Institute of Engineering Medicine, Key Laboratory of Molecular Medicine and Biotherapy, Beijing Institute of Technology, Beijing 100081, China

2 Department of Polymer Science and Technology, School of Chemical Engineering and Technology, Key Laboratory of Systems Bioengineering of the Ministry of Education, Tianjin University, Tianjin 300072, China

3 School of Pharmacy, Hunan University of Chinese Medicine, Changsha 410208, China

Received: 27 June 2020 / Accepted: 18 August 2020 / Published online: 23 November 2020

\section{Graphical abstract}

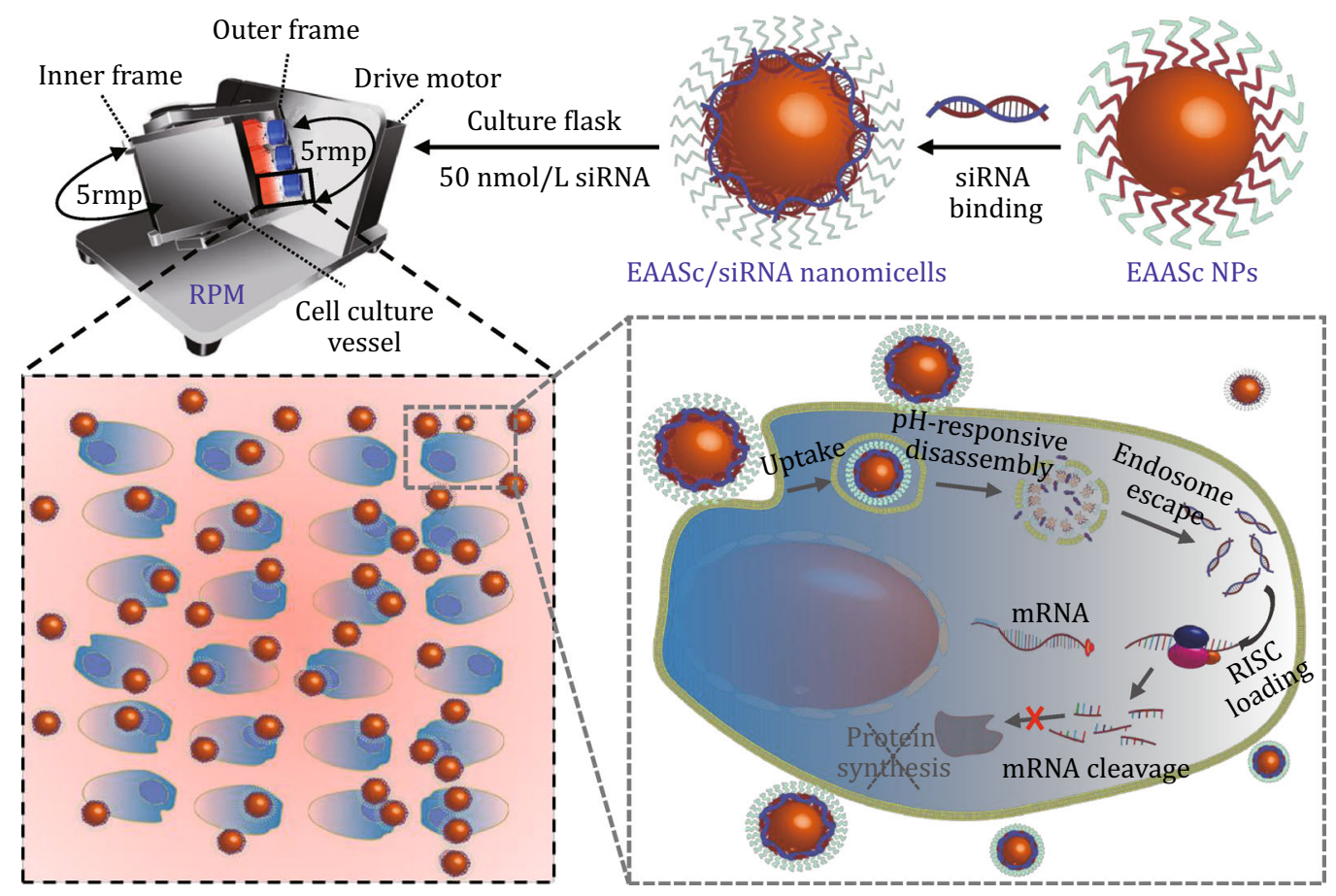

Electronic supplementary material The online version of this article (https://doi.org/10.1007/s41048-020-00121-y) contains supplementary material, which is available to authorized users.

$\bowtie$ Correspondence: yyhuang@bit.edu.cn (Y. Huang) 
Abstract Microgravity (MG) effect is a weightlessness phenomenon caused by the distance from the ground or low gravity of other planets outside the earth's atmosphere. The various effects of MG have been corroborated in human and animal studies and modeled in cell-based analogs. However, the impact of MG on siRNA performance remains to be elucidated, which is crucial for aerospace medicine. In this study, we prepared nucleic acid nanomicelles (EAASc/siRNA) by using tri-block copolymer of $\mathrm{PEG}_{45^{-}}$ $\mathrm{PAMA}_{40}-\mathrm{P}\left(\mathrm{C}_{\mathrm{A}} \mathrm{A}_{36}-\mathrm{DBA}_{37}\right)$ (EAASc) and siRNA and explored its working mechanism under simulated microgravity (SMG) condition generated by a random positioning machine (RPM). The binding ability of EAASc to siRNA and silence activity were firstly confirmed in normal gravity (NG) environment. Evaluation of PLK1 mRNA expression revealed that gene inhibition efficiencies were increased by 28.7\% (HepG2) and 28.9\% (A549) under SMG condition, compared with those under NG condition. In addition, mechanism exploration indicated that morphology and migration capability of cancer cells were significantly changed, the internalization of EAASc/siRNA by cells was magnified when the cells were incubated with RPM. No significant difference was observed regarding the expression profiles of genes involved in RNA interference (RNAi) pathway, including Ago2, Dicer, TRBP, and so on. Taken together, siRNA activity was elevated under SMG condition owning to increased cellular internalization. This study, for the first time to our knowledge, provides valuable theory for development and application of siRNA therapeutic in space in the future.

Keywords Microgravity, siRNA, Polymer, PLK1, Space pharmaceutics, Aerospace medicine

\section{INTRODUCTION}

In the process of the rapid development of human demand for space exploration, the impact of the extreme environment on astronauts has attracted much attention (Egorov 1996; Ohta et al. 2002), which has become the biggest challenge for long-term human habitation and space exploration. Through the innovation of aerospace technology, many detrimental conditions, such as extreme temperature and ionizing radiation, can be gradually or partially solved. However, exposure to microgravity (MG) is still an unexplored issue (Loomer 2001). Microgravity effect is a weightlessness phenomenon caused by the distance from the ground or the low gravity of other planets (Clement and Pavy-Le Traon 2004). As one of the characteristics of the space environment, microgravity effects have multiple influences on organisms that adapt to ground gravity, which greatly limit space flight.

The action rules and mechanisms of various organelles and cells that were unveiled under normal gravity (NG) may be differ greatly, even completely, in the space environment. Previous studies have shown that the effect of microgravity can cause a series of physiological changes in organisms (Li et al. 2009), affecting the cytoskeleton system (Crawford-Young 2006), periodic regulation system (Paulsen et al. 2015) and the signal transduction pathway of cells (Kong et al. 2019). Under microgravity conditions, ocular abnormalities including unilateral and bilateral optic disk edema, optic nerve sheath dilatation, eyeball flattening, choroidal folding, and hyperopic displacement were observed (Wostyn et al. 2019). The structural changes of the brain (Roberts et al. 2019), the enlargement of left atrium and the decrease of blood flow during left internal jugular vein thrombosis were also reported (Norsk 2020). Change of body fluid replacement, decreased bone and muscle density, and decreased immunity, may also happen. In addition, microgravity environment can also affect the growth and process of tumor cells (Jhala et al. 2014), leading to changes in the phenotype and characteristics of breast cancer (Bauer et al. 2018; Masiello et al. 2014), the differentiation and apoptosis status of follicular thyroid carcinoma cells (Grimm et al. 2002), and the metastasis of lung cancer (Ahn et al. 2019; Eyal and Derendorf 2019). This series of changes together may significantly affect the treatment effect of certain therapeutics in space. Although medicines have been used for more than half a century to circumvent various challenges in space, the effects of microgravity on pharmacokinetics, pharmacodynamics and the intrinsic mechanism of drugs remain to be elucidated. Therefore, theory exploration and technique platform establishment are of essential importance for drug development and application in space. 
Small interfering RNA (siRNA) is considered to be one of the most strategic pharmaceutical technologies in the post-genomic era ( $\mathrm{Hu}$ et al. 2020). siRNA can interfere with almost all genes by acting on messenger RNA, which can treat diseases by silencing the expression of pathogenic genes (de Fougerolles et al. 2007; Hu et al. 2019; Weng et al. 2019). Currently, over 40 kinds of siRNA formulations are undergoing clinical trials, and dozens of them are investigated in phase IIb/III stage. Two siRNA therapeutics, Onpattro and Givlaari, have been approved by the US Food and Drug Administration (FDA) in 2018 and 2019, for the treatment of the polyneuropathy (Hoy 2018; Huang 2019; Weng et al. 2019) and acute hepatic porphyria (GonzalezAseguinolaza 2020; Scott 2020), respectively. As a future pharmaceutic modality, siRNA possesses promising prospects in treating human diverse disorders, especially if the delivery issue is solved effectively (Zhang et al. 2020; Zhao et al. 2020). Therefore, elucidation of working mechanism under simulated microgravity (SMG) condition is meaningful for establishing theory system and guideline of siRNA application in space.

At present, few cases were reported on the employment of siRNA in SMG environment. Shi et al. utilized siRNA targeting intraflagellar transport protein 88 (IFT88) to investigate the physiological mechanisms of microgravity-induced bone deterioration (Shi et al. 2017, 2020). siRNA against early growth response 1 and 2 (Egr1/2) was applied to explore the mechanism of unloading-mediated muscle atrophy (Uchida et al. 2018). Li et al. demonstrated that knockdown of CD44 using siRNA inhibited the alteration of osteoclast function induced by SMG (Li et al. 2020). However, the influence of microgravity on siRNA transfection into targeted cell and following silencing process has not been studied, to our knowledge. It is a fundamental issue for the application of siRNA in both basic research and disease treatment in space.

In this study, we used a pH-sensitive tri-block copolymer of $\mathrm{PEG}_{45}-\mathrm{PAMA}_{40}-\mathrm{P}\left(\mathrm{C} \mathrm{A}_{36}-\mathrm{DBA}_{37}\right)$ (EAASc) to formulate siRNA, and investigated the performance of EAASc/siRNA in cancer cells under SMG condition generated by random positioning machine (RPM) (Fig. 1). Gene inhibition, cell morphology and migration, cellular uptake, and the expression profiles of key factors involved in RNA interference (RNAi) pathway (Ago2, Dicer, Hsp90, TRBP and PACT) were analyzed. As a result, we observed that the silencing activity of EAASc/siRNA was enhanced under SMG condition, which was owing to elevated internalization by the cancer cells.

\section{RESULTS}

\section{Validation of polymer's delivery efficiency in NG environment}

Before exploring the effects of microgravity on siRNA transfection and gene silence, we need to confirm that the polymer used in this study has excellent siRNA transfection efficiency under NG condition. It is reported that $\mathrm{pKa}$ value or $\mathrm{pH}$-responsive property of delivery carrier plays essential role in delivering siRNA and mediating efficient endosomal escape (Du et al. 2018; Whitehead et al. 2014; Zhou et al. 2016). Previously, we have investigated the influence pattern of $\mathrm{pKa}$ value on siRNA delivery by using a series of tri-block polymers (Du et al. 2018). In this study, three polymers, named EAASc, EAASd, and EAASe (Fig. 1A, supplementary Fig. S1), were selected to validate their delivery efficiencies. In detail, EAASc, EAASd and EAASe are triblock copolymers with different hydrophobic segments of PEG-PAMA-P(C6Ax-C7Ay-DPAz-DBAm) (EAAS). PEG and PAMA are poly (ethylene glycol) and poly (aminoethyl methacrylate), respectively. PEG is widely used to modify therapeutic agents because it can improve the pharmacokinetic property and reduce unspecific protein binding in circulation, thereby erase undesired adverse effects. PAMA is a cationic polymer that can bind siRNA via electrostatic interaction. The $\mathrm{pKa}$ values of 2 -(pentamethylene imino) ethyl methacrylate (C6A-MA), 2-(hexamethylene imino) ethyl methacrylate (C7A-MA), 2-(diisopropyl amino) ethyl methacrylate (DPA-MA), and 2-(dibutyl amino) ethyl methacrylate (DBA-MA) are 7.0, 6.8, 6.2, and 5.2, respectively ( $\mathrm{Du}$ et al. 2018). Therefore, polymers with different $\mathrm{pKa}$ values can be obtained by adjusting the numbers and the types of hydrophobic amine monomers. The numbers of $x, y, z$, and $m$ of EAASc are $0,36,0$, and 37, respectively (Fig. 2A). The numbers of $x, y, z$, and $m$ of EAASd are 35, 0,0 , and 35 , respectively (supplementary Fig. S1A). The numbers of $x, y, z$, and $m$ of EAASe are $0,0,43$, and 0 , respectively (supplementary Fig. S1B). As a result, the $\mathrm{pKa}$ values of EAASc, EAASd, and EAASe are 5.8, 6.0, and 6.2, respectively (Du et al. 2018). Three nanomicelles of EAASc/siRNA, EAASd/siRNA and EAASe/siRNA were prepared simply by mixing the solutions of polymer and siRNA (Fig. 1A).

Firstly, we investigated the binding capacity of polymers to siRNA by gel retardation assay (Fig. 2A). The mass ratios of polymer and siRNA ranged from 3:1 to 15:1. It was observed that all three polymers exhibited robust siRNA binding capacity because all siRNAs were entrapped in gel wells when the mass ratios of polymer and siRNA were higher than 6:1. Mass ratio of 9:1 was 
A

A
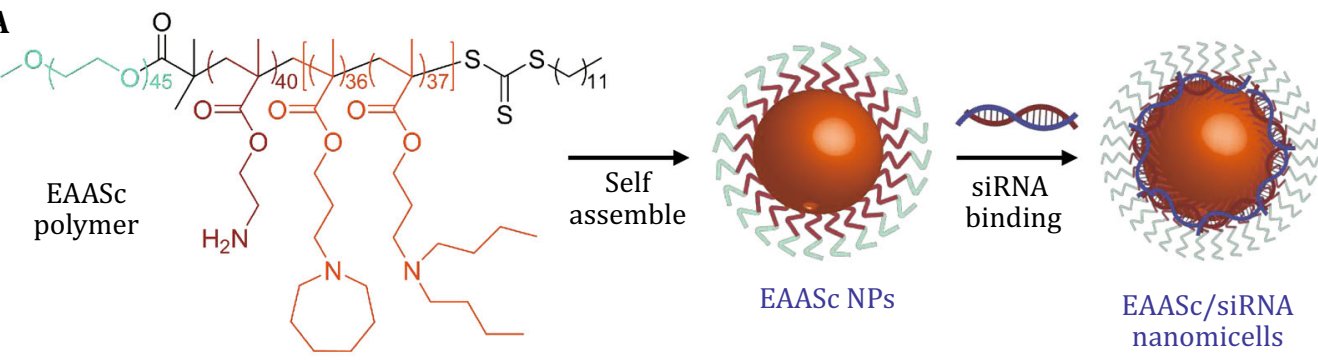

EAASc NPs

EAASc/siRNA nanomicells

B Outer frame

D

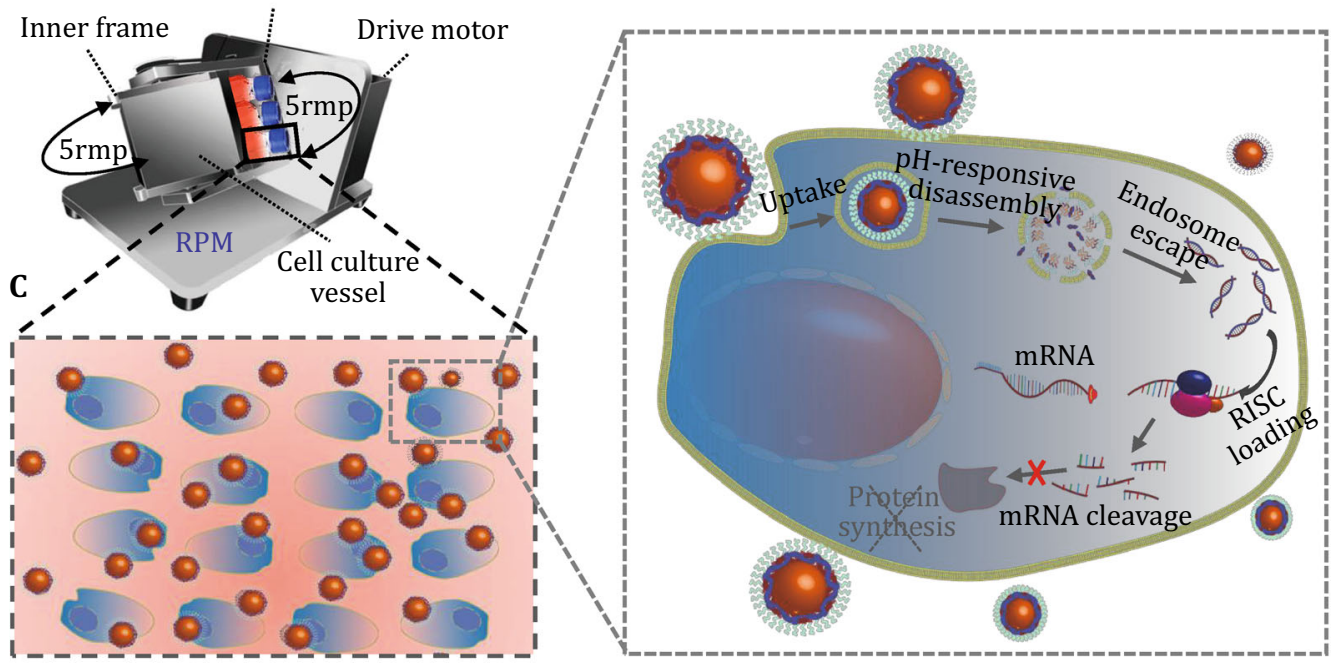

Fig. 1 Schematic illustration of siRNA transfection and gene silence in a SMG environment. A Chemical structure of EAASc polymer and the nanomicelle preparation process. B A RPM was used to establish SMG environment. C Schematic illustration of cells incubated in the flask fixed on the RPM. D Transmembrane transportation of EAASc/siRNA nanomicelles and gene silencing process in cells

used in following studies to ensure siRNAs were completely formulated.

Secondly, we analyzed the cytotoxicity of these three nanomicelles (mass ratio, 9:1) by using a scramble siRNA (siNC) at a transfection concentration of $50 \mathrm{nmol} / \mathrm{L}$ in HepG2-Luc, a liver cancer cell line stably expressing firefly luciferase. Commercial Lipofectamine 2000 (Lipo2000) was included as control. MTTrecorded cell viabilities manifested that all testing formulations including Lipo2000/siNC, EAASc/siNC, EAASd/siNC, and EAASe/siNC showed ideal biocompatibility in vitro. The remaining cell viabilities of these four formulations were $107.4 \%, 87.5 \%, 85.8 \%$, and $76.1 \%$, respectively, compared to the mock control (Fig. 2B).

We further examined the gene silencing efficiencies of these formulations by using siRNA targeting firefly luciferase (siLuc) at a transfection concentration of $50 \mathrm{nmol} / \mathrm{L}$ in HepG2-Luc. Twenty-four hours after transfection, luciferase activity was determined by adding substrate of firefly luciferase. It was clearly observed that all the four testing formulations significantly downregulated the expression of luciferase, with inhibition efficiencies of $66.1 \%, 69.5 \%, 46.8 \%$, and
69.5\% for Lipo2000/siLuc, EAASc/siLuc, EAASd/siLuc, and EAASe/siLuc, respectively (Fig. 2B). In consideration of that the cell viability directly influences the detection of luciferase activity, we normalized the remaining luciferase activity with the cell viabilities data. As shown in Fig. 2C, the silencing pattern was similar to that in Fig. 2B, as the inhibition efficiencies of Lipo2000/siLuc, EAASc/siLuc, EAASd/siLuc and EAASe/siLuc were $68.5 \%, 65.1 \%, 38.0 \%$, and $60.0 \%$, respectively (Fig. 2C). Taken together, EAASc, the leading polymer in this group, was selected to perform following assays.

\section{Effect of SMG on gene silence}

To investigate whether microgravity influences siRNAmediated gene silence, HepG2, HepG2-Luc and A549 were employed to evaluate the endogenous gene expression by using siRNAs targeting polo-like kinase 1 (PLK1) (siPLK1) or firefly luciferase (siLuc). PLK1 is an important gene involved in regulating cell cycle, plays essential role in cancer initiation, progression, prognosis, and drug resistance (Liu et al. 2017; Wu et al. 2018). 
A
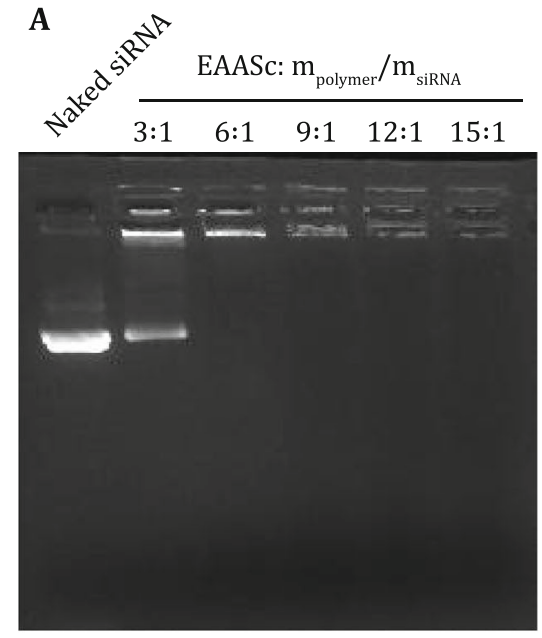

B

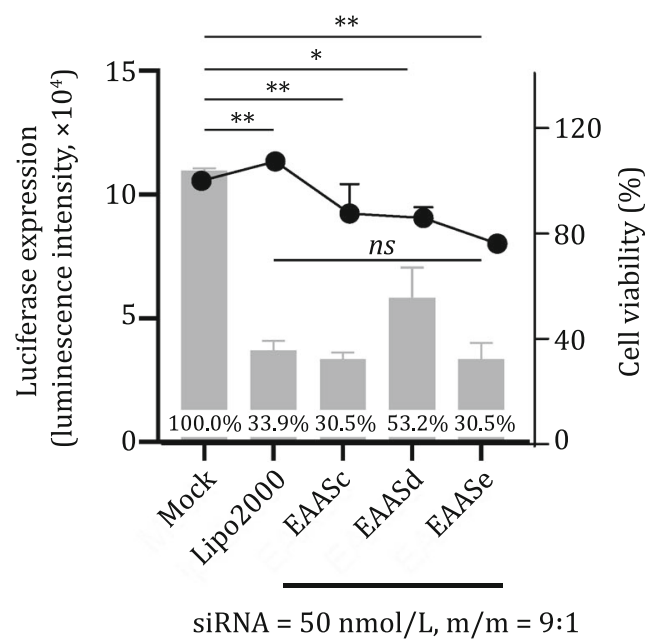

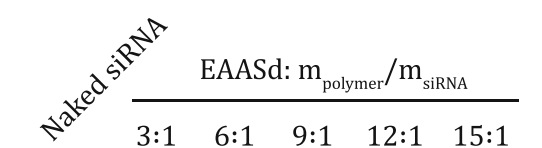
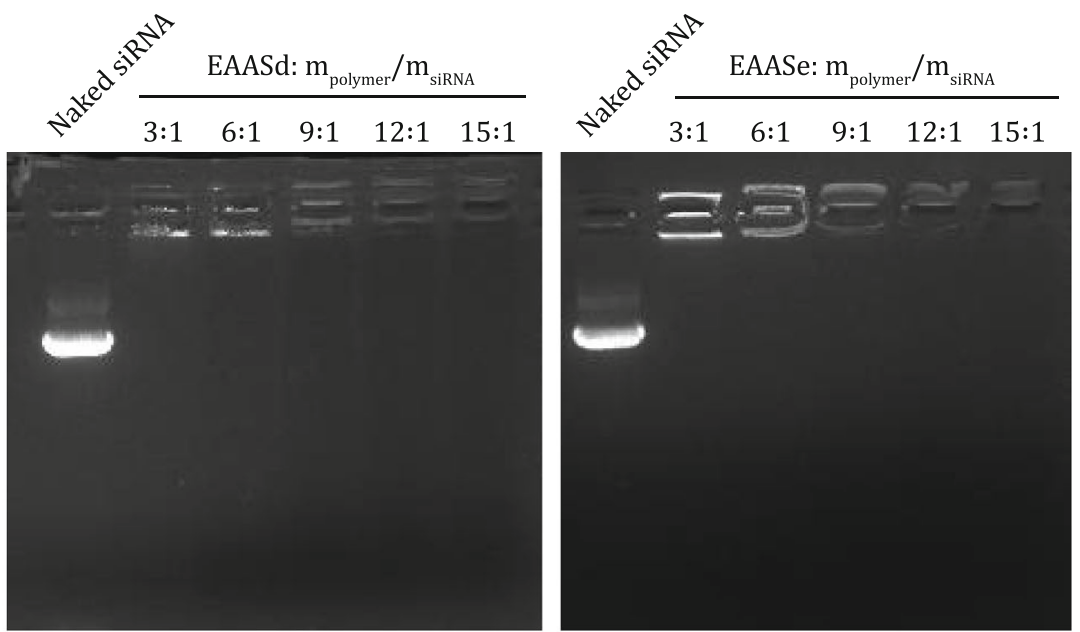

C

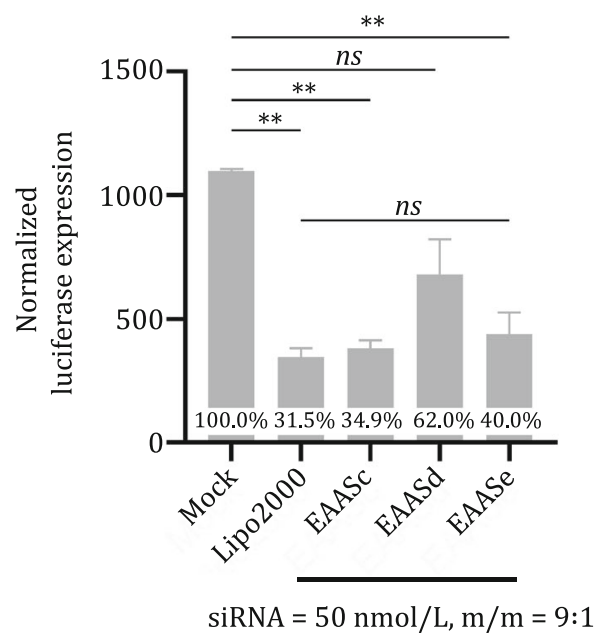

Fig. 2 Capacity validation of polymers in loading siRNA and mediating gene silence. A Gel retardation of nanomicelles of EAASc/siRNA, EAASd/siRNA, and EAASe/siRNA at mass ratios of 3:1, 6:1, 9:1, 12:1, and 15:1 (polymer: siRNA). B Luciferase expression and cell viability after transfection of polymer-siRNA nanomicelles under NG condition. C Normalized luciferase expression in HepG-Luc cells when dividing the luminescence intensities by corresponding cell viability values. The percentages inserted in the bars of $\mathbf{B}$ and $\mathbf{C}$ represent the relative luciferase expression compared to the mock control. ${ }^{*} p<0.05$; ${ }^{*} p<0.01$; ns: non-significant difference was observed

TKM-080301, a liposome formulation containing a siRNA targeting PLK1, once was investigated in phase 2 clinical trial for the treatment of solid tumor (El Dika et al. 2019). Recent studies suggested that PLK1 is also a proviral host factor for hepatitis B virus replication (Diab et al. 2017). The inhibition of PLK1's expression is also favorable for treating hepatitis B (Foca et al. 2020). Therefore, understanding the behavior of PLK1targeting siRNA under microgravity condition will help us to design and develop therapeutics in space.

It was observed that gene silencing efficiency of EAASc/siPLK1 under SMG condition is significantly higher than that under NG condition (Fig. 3A), as the inhibition efficiency of EAASc/siPLK1 increased from $14.4 \%(\mathrm{NG})$ to $43.1 \%$ (SMG). It is worth noting that PLK1 mRNA expression of EAASc/siPLK1-treated cells under SMG condition was normalized to that of mock control under SMG condition, to eliminate the effect of microgravity on PLK1 expression. The same analysis was performed for NG-mock and NG-EAASc/siPLK1 groups. In addition, luciferase inhibition was evaluated in HepG2-Luc by using siLuc. Luciferase expressions in groups of NG-EAASc/siLuc, SMG-mock and SMG-EAASc/ siLuc are significantly lower than that of NG-mock, suggesting both siRNA and microgravity reduced luciferase expression (Fig. 3B). To compare the silencing efficiency more accurately, luciferase expressions in NGEAASc/siLuc and SMG-EAASc/siLuc were normalized to those in NG-mock and SMG-mock, respectively. As shown in Fig. 3C, EAASc/siLuc applied under SMG condition increased the inhibition efficiency from $45.3 \%$ to $67.2 \%$, compared to that applied under NG condition. 
A

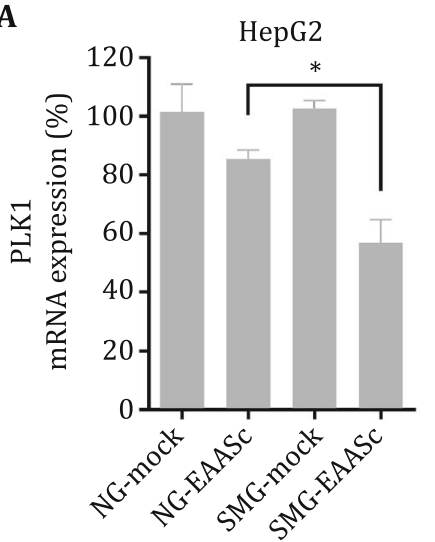

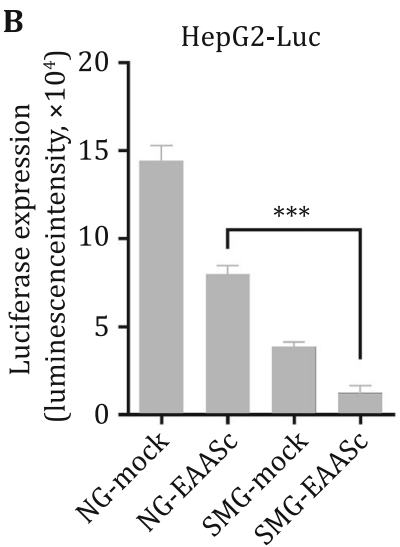
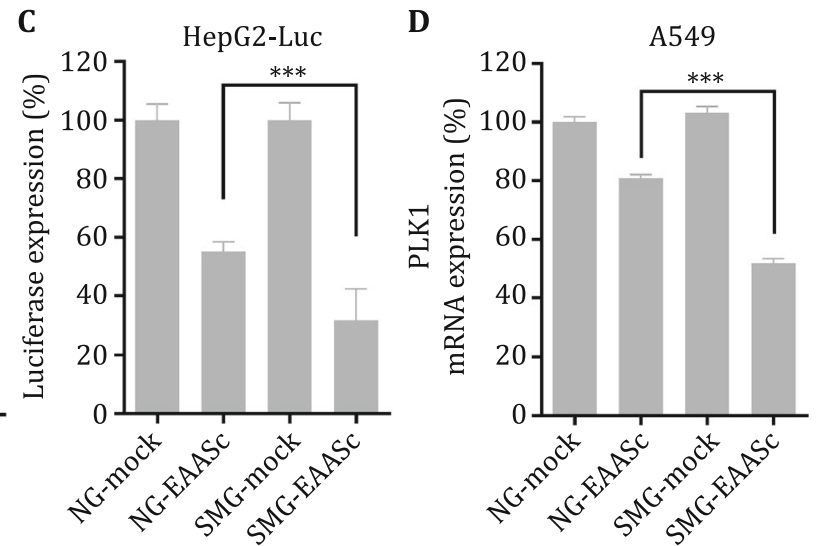

Fig. 3 Gene silencing activity of EAASc/siRNA nanomicelles in HepG2, HepG2-Luc and A549 cells cultured in NG or SMG environment. A Relative mRNA expression of PLK1 in HepG2 cells after treating with EAASc/siPLK1 for $24 \mathrm{~h}$. B Luminescence intensities of HepG2-Luc cells after being treated with EAASc/siLuc. C Normalized luciferase expression of B. The luminescence intensities of cells treated with EAASc/siLuc under NG or SMG conditions were normalized to those of cells receiving mock treatment, respectively. D PLK1 mRNA expression in A549 cells after treating with EAASc/siPLK1 for 24 h. ${ }^{*} p<0.05,{ }^{* * *} p<0.001$

Furthermore, A549, a lung cancer cell line, was used to explore the gene silencing pattern. Data manifested that the silencing activity of siPLK1 under SMG condition (48.1\% inhibition efficiency) also was dramatically higher than that under NG condition $119.2 \%$ inhibition efficiency) (Fig. 3D). Taken together, these data suggested that SMG treatment robustly enhanced the silencing activity of siRNA that was transfected with EAASc.

\section{Influence of SMG on cell morphology and migration}

To explore the mechanism of microgravity enhancing gene silencing efficiency, we firstly analyzed the effects of SMG on cell morphology and migration. It was observed that the cell morphology was significantly changed after incubating in SMG environment for $24 \mathrm{~h}$ (Fig. 4A). Meanwhile, transwell assay conducted in HepG2 and A549 cells suggested that the migration ability of these two cancer cells was remarkably decreased after treating with SMG (Fig. 4B). To our knowledge, the change of cell morphology involves the reconstruction of the cytoskeleton of cells, which may affect the permeability of the cell membrane. Accordingly, the transmembrane transportation of EAASc/ siRNA may be also affected.

\section{Cellular uptake of EAASc/siRNA under SMG condition}

To evaluate the cellular uptake efficiency of EAASc/ siRNA, confocal imaging and fluorescence activated cell sorting (FACS) were performed by using Cy5-labeled
A

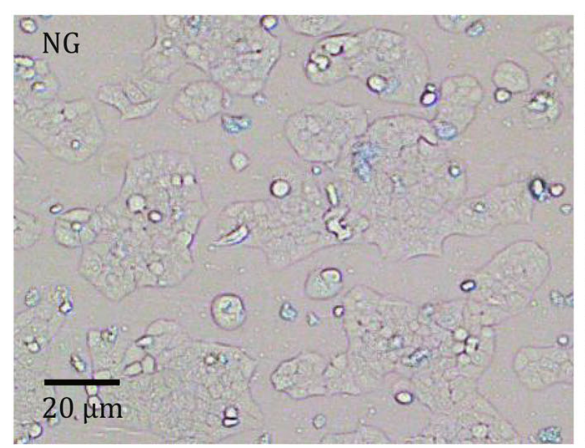

B

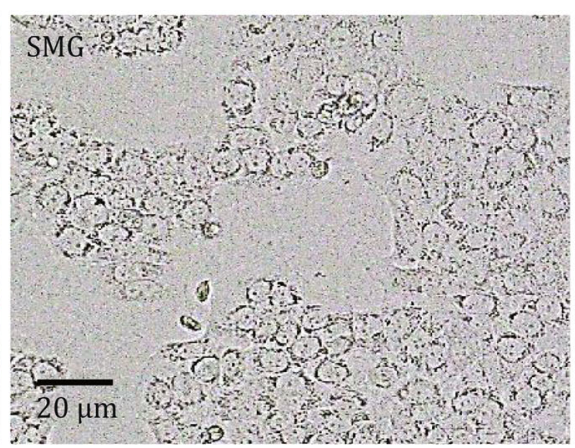

C

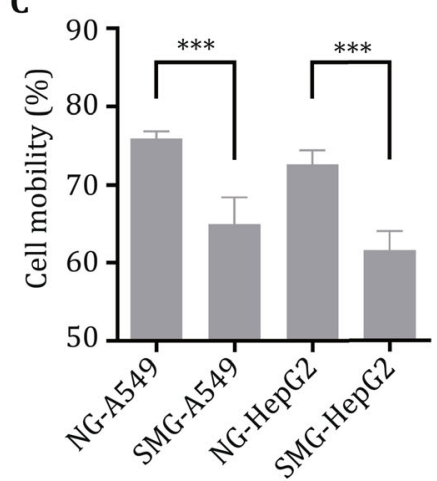

Fig. 4 The effects of SMG on cell morphology and migration. A The cell morphology of HepG2 cultured in NG environment. B The cell morphology of HepG2 cells receiving SMG treatment. C The changes of cell mobility of A549 and HepG2 after being cultured under SMG condition. ${ }^{* * *} p<0.001$ 
siRNA. Significant internalization was observed for HepG2 cells cultured under either NG or SMG conditions (Fig. 5A). Flow cytometry data revealed that $56.8 \%$ and $79.2 \%$ cells have internalized EAASc/siRNA nanomicelles for cells incubated in NG and SMG environments, respectively (Fig. 5B). Quantitative analysis data further confirmed the observations (Fig. 5C). These data suggested that the transfection efficiency of siRNA was improved under the condition of microgravity, which may contribute to the elevated gene silencing efficiency under this condition.

\section{Expression profiles of genes involved in RNAi pathway}

To further investigate the mechanism of SMG-induced elevation of gene silence, we analyzed the expression profiles of pivotal genes involved in RNAi pathway, including Argonaute 2 (Ago2), Dicer, heat shock protein 90 (Hsp90), transactivation response RNA binding protein (TRBP). and protein kinase RNA activator (PACT). These factors are the components of RNA induced silencing complex (RISC) or the key enzyme for producing mature siRNA. They may also enhance siRNA activity via activating related kinases. Real-time quantitative PCR results proved that the expression profiles of these five genes were similar when the cells were cultured under NG or SMG condition for $24 \mathrm{~h}$. The same patters were recorded in both HepG2 and A549 cells (Fig. 6). Taken together, the expression of key genes involved in RNAi pathway was not significantly affected by the microgravity. Therefore, microgravity-induced changes in cell morphology, cell permeability, and cellular entry of siRNA are the determinants of enhanced gene silencing efficiency under SMG condition.
A

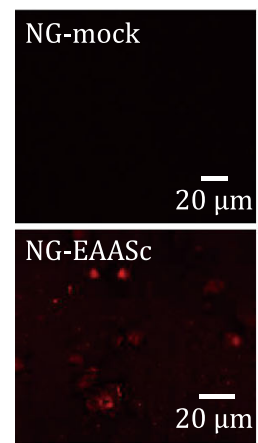

B

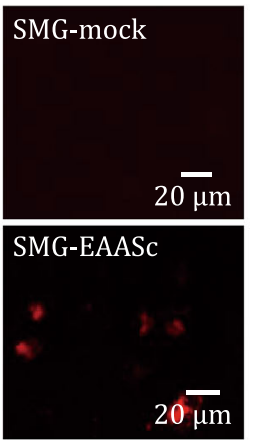

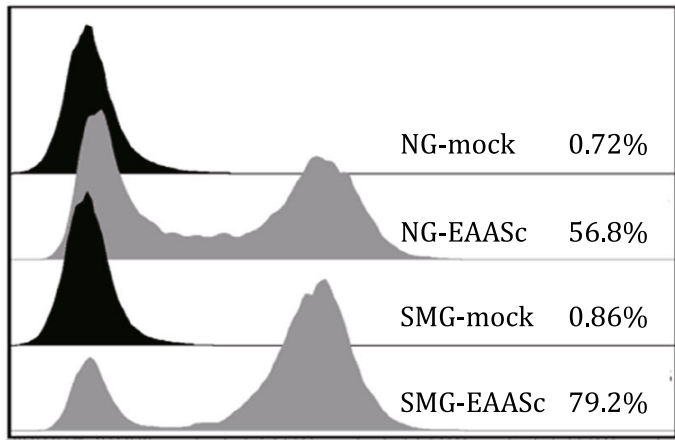

C

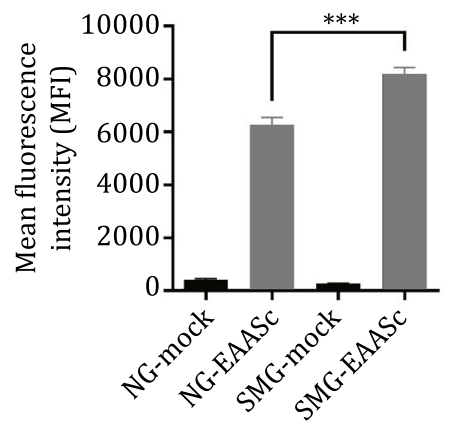

Fig.5 The effect of SMG on cellular uptake of EAASc/siRNA by HepG2 cells. A Confocal images of HepG2 cells that were transfected with EAASc/Cy5-siRNA under NG or SMG condition. Scale bar, $20 \mu \mathrm{m}$. B FACS recording of internalization of EAASc/Cy5-siRNA by HepG2 cells. C Quantitative analysis of the FACS data. ${ }^{* * *} p<0.001$
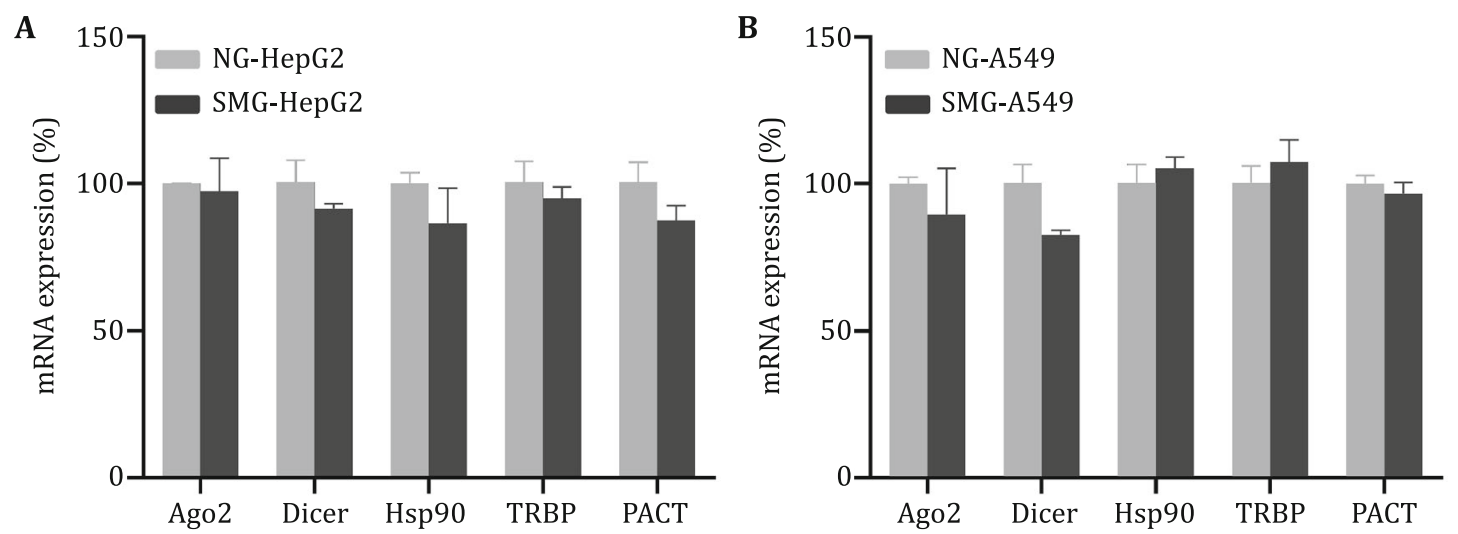

Fig. 6 Expression profiles of key genes involved in RNAi pathway. A Relative gene expression of Ago2, Dicer, Hsp90, TRBP, and PACT in HepG2 cells receiving NG or SMG treatment. B mRNA expression of these five genes in A549 cultured with normal incubator or random positioning machine 


\section{DISCUSSION}

Drug discovery, development, or manufacture in space is an extremely important area in the future. It not only is a central task to ensure the health of astronauts, but also will bring unprecedented benefits to the normal life of people on earth (Eyal and Derendorf 2019). However, physiological changes during space flight may significantly affect the efficacy and safety of drugs. Comprehensively understanding the effects of microgravity on the structures of nucleic acids, proteins, and saccharides, as well as the expression profiles and functional changes of bioactive molecules are the fundamental issue to develop and use medicine in space (Braddock 2020). Precise molecule design can be performed if the structure of the targeted protein has been unveiled. Researchers have observed that protein crystals grown in microgravity environment contain fewer imperfections than those grown on earth. Therefore, the investigation of structural biology in the microgravity environment is crucial and promising for developing small molecule and antibody therapeutics that interact with their targeting protein based on spatial conformation.

For example, Merck \& Co. used the orderly crystals to formulate antibody of $\operatorname{Keytruda}^{\circledR}$, a cancer immunotherapy drug targeting programmed cell death protein 1 (PD-1) (Reichert et al. 2019). By leveraging the microgravity effect to reduce deposition and minimum convection, they produced uniform crystal suspensions with single-peak of particle size distribution $(39 \mu \mathrm{m})$ in high yield in a commercial SpaceX spacecraft, while two peaks of particle size distribution (13 and $102 \mu \mathrm{m}$ ) were observed if preparing the formulation on the Earth. The flight crystalline suspensions were less viscous and were sedimented more uniformly than those prepared on the ground. These efforts may help to broaden the choice of drug development to improve the safety and quality of life of patients. In addition, the Michael J. Fox Foundation tried to develop therapeutic agents for treating Parkinson's disease based on protein crystals of the leucine-rich repeat kinase 2 (LRRK2) grown in space. Oak Ridge National Laboratory also has made efforts to develop an antidote for nerve gas and pesticide poisoning by using crystals of acetylcholinesterase (AChE) obtained in space.

RNA interference (RNAi) is an ancient phenomenon used to protect the host from infection by foreign organisms, such as viruses. Since its discovery in 1998, it has become a promising tool and pharmaceutical modality in basic research and treating life-threaten diseases. In the microgravity environment, Wang et al. observed that the expression of the Hmga2 gene is inhibited by regulating miR-33-5p (Wang et al. 2016), and Qin et al. concluded that the expression of miRNA494 gene was significantly upregulated. However, it is unknown what will happen to siRNA, the most important therapeutic form of RNAi family, when it is applied in space or microgravity environment.

In this study, we firstly identified an efficient siRNA transfection reagent named EAASc, demonstrated that EAASc/siRNA nanomicelles triggered higher gene silence in cultured cancer cells under SMG condition than that under NG condition. Mechanism explorations suggested that the morphology, migration capability, and permeability of cancer cells were affected, while the expressions of decisive genes involved in RNAi pathway was not significantly affected by microgravity. It is reported that microgravity can change the expression of cytoskeletal protein or lead to rearrangement of the cytoskeleton network (Strube et al. 2020). This is confirmed by our data that the Ct (cycle threshold) values of $\beta$-actin in cells treating with SMG are different from those in cells treating with NG (data not shown). These changes will directly influence the morphology, movement capability, and cellular uptake of extracellular payloads (such as EAASc/siRNA nanomicelles), in line with what we observed in this study. Therefore, we concluded that enhanced internalization of EAASc/ siRNA is the dominant factor of elevated gene silencing efficiency under SMG condition, compared with the profile in NG environment. To the best of our knowledge, this is the first time to study the effect of SMG on siRNA transfection and gene silencing and to unveil the potential biological mechanism. It is meaningful for future RNAi drug development in space, and making therapeutic regimen for astronauts or space travelers in the future.

\section{MATERIALS AND METHODS}

\section{Materials}

Dulbecco's modified Eagle's medium (DMEM), fetal bovine serum (FBS), Lipofectamine 2000, trypsin, OptiMEM, and penicillin-streptomycin were purchased from Invitrogen Corporation. Transwell ${ }^{\mathrm{TM}}$ was purchased from Sigma-Aldrich. EAASc, EAASd, and EAASe were synthesized by the chemical Laboratory of Tianjin University. The detailed material information can be found in the previous paper ( $\mathrm{Du}$ et al. 2018). All the primers used in the research were synthesized from Beijing Platinum Biotechnology Co., Ltd. Cy5-labeled siRNA (Cy5-siRNA), negative control siRNA (siNC), antifirefly luciferase siRNA (siLuc), and anti-PLK1 siRNA 
(siPLK1) were provided by Suzhou Ribo Life Science Co., Ltd. (Suzhou, Jiangsu Province, China). All siRNAs used in this study were shown in supplementary Table S1.

\section{Cell culture}

A549 (a lung cancer cell line), HepG2 (a hepatoma cell line), and HepG2-Luc (a cell line stably expressing firefly luciferase) used in this study were kept in Beijing Institute of Technology. The cells were cultured in DMEM with $10 \%$ FBS, 100 unit/mL penicillin, $100 \mathrm{~g} / \mathrm{mL}$ streptomycin and were cultured in an incubator at $37{ }^{\circ} \mathrm{C}$ with $5 \% \mathrm{CO}_{2}$.

\section{Establishment of SMG environment}

In order to ensure accuracy, it is necessary to control the cell density at $2 \times 10^{5}$, and to make sure the cells grow at monolayer after transferred to T-25 culture flask with $10 \mathrm{~mL}$ medium. Then the cells were cultured by a random positioning machine (RPM) that was installed on a microgravity gyroscope. RPM simulates the principle of microgravity so that vector averages of gravity are analyzed based on mechanical angles. The cells are at the bottom of the T-25 culture flask, and the direction of gravity is changing constantly. RPM removes the effects of gravity by causing T-25 culture flask to rotate along two separate axes, changing its direction at a constant velocity and relative to the gravity vector. Generally, there are two considerations for setting RPM running parameters: centrifugal force is less than $10^{-3} \mathrm{~g}$; the trajectory covers the entire sphere. RPM runs for $2 \mathrm{~h}$ at a rotation speed of $5 \mathrm{r} / \mathrm{min}$, and the proportion of points simulating microgravity effect in the whole area reaches $98 \%$ and the coverage rate reaches $80 \%$. To make simulating microgravity effect to cover the whole bottle, we adopted RPM to run $24 \mathrm{~h}$ at a speed of $5 \mathrm{r} / \mathrm{min}$ to simulate the microgravity environment. After incubation for $24 \mathrm{~h}$, the cells will be completely attached to the wall of flask. Air bubbles may be generated in the process of microgravity simulation. T-25 culture flask has large shear force at the bottom when the RPM is very high. But it is needed to avoid generating bubbles because bubble can induce shearing force to damage the cells.

\section{Gel retardation}

siRNA binding ability of the polymers was evaluated by agarose gel retardation. Polymers of EAASc, EAASd, or EAASe were mixed with siRNA $(0.4 \mu \mathrm{g})$ targeting pololike kinase 1 (PLK1) at different mass ratios (3:1, 6:1, 9:1, 12:1, and 15:1). After incubation for $20 \mathrm{~min}$ at room temperature, $15 \mu \mathrm{L}$ of the nanomicelles was mixed with $6 \times$ loading buffer $(3 \mu \mathrm{L})$. Then the mixture was loaded in $2 \%(w / v)$ agarose gel. $1 \times$ TAE running buffer was used during electrophoresis, then the electric field was applied at a voltage of $120 \mathrm{~V}$ for $20 \mathrm{~min}$. Finally, the gel was detected by a gel imaging system (Bio-Rad, Hercules, CA) under the ultraviolet wavelength of $254 \mathrm{~nm}$.

\section{Luciferase assay}

HepG2-Luc cells stably expressing firefly luciferase were cultured in the flask and used to determine the silencing activity of anti-luciferase siRNA (siLuc) formulated by EAASc, EAASd, or EAASe. The cells were seeded in 24-well plates at the density of $5 \times 10^{4}$ cells per well one day before transfection. Then $0.5 \mathrm{~mL}$ of Opti-MEM was used to replace the culture medium. Nanomicelles of EAASc/siLuc, EAASd/siLuc, or EAASe/siLuc at mass ratio of 9:1 were added into the cells at a transfection concentration of $50 \mathrm{nmol} / \mathrm{L}$ (for siRNA). After incubation for $4 \mathrm{~h}$, Opti-MEM medium was replaced by $1 \mathrm{~mL}$ of DMEM, followed by incubating for another $20 \mathrm{~h}$. Then the culture medium was removed. The cells were washed by precooled PBS for three times, followed by adding $100 \mu \mathrm{L}$ of cell passive lysis buffer, shaking for $30 \mathrm{~min}$, and centrifuging at $12,000 \mathrm{r} / \mathrm{min}$ for $1 \mathrm{~min}$. Finally, $10 \mu \mathrm{L}$ of the supernatant was transferred to the reading plate, and the luciferase activity was determined by adding $50 \mu \mathrm{L}$ of reaction substrate solution and recording with microplate readers (BioTek, USA).

\section{Cell viability}

HepG2 cells were seeded in 96-well plates $24 \mathrm{~h}$ before transfection. Nanomicelles of EAASc/siLuc, EAASd/ siLuc, or EAASe/siLuc were also transfected to the cells at siRNA concentration of $50 \mathrm{nmol} / \mathrm{L}$. Scramble siRNA (negative control siRNA, siNC) was used to eliminate the impact of gene silence on cell viability. Twenty-four hours later, $10 \mu \mathrm{L}$ of MTT ( $5 \mathrm{mg} / \mathrm{mL}$ ) was added to each well. After incubating in the incubator for $4 \mathrm{~h}, 50 \mu \mathrm{L}$ of DMSO was added to dissolve formazan crystals. Finally, the DMSO absorbance at $540 \mathrm{~nm}$ was measured by a microplate reader (BioTek, USA) with a reference wavelength of $650 \mathrm{~nm}$. The untreated cells were used as the control group (mock). Cell viability was calculated according to the following formula:

Cell viability $(\%)=\frac{O D 540(\text { sample })-O D 650(\text { sample })}{O D 540(\text { mock })-O D 650(\text { mock })}$ $\times 100$. 


\section{Confocal observation and flow cytometry}

The HepG2 cells were seeded in $25-\mathrm{cm}^{2}$ flask and incubated under SMG condition for $24 \mathrm{~h}$. Then the DMEM was replaced with Opti-MEM, and EAASc/Cy5siRNA was transfected at a concentration of $50 \mathrm{nmol} / \mathrm{L}$ (for siRNA). After incubation for $4 \mathrm{~h}$ under SMG condition, the cells were observed with an inverted confocal microscope (Nikon, Japan). Alternatively, the cells can be washed with precooled $1 \times$ PBS for three times, followed by digesting with $0.25 \%$ trypsin and centrifuging at $1000 \mathrm{r} / \mathrm{min}$ for $5 \mathrm{~min}$. Then the cells were resuspended and washed for three times with PBS again. Finally, the cells were resuspended in $400 \mu \mathrm{L}$ of $1 \times$ PBS and analyzed with flow cytometry (Becton Dickinson, San Jose, CA, USA).

\section{Cell migration}

HepG2 and A549 cells were used to evaluate the impact of microgravity on cancer cells' migration, respectively. Cells were seeded in $25-\mathrm{cm}^{2}$ flask and incubated under SMG condition, or NG condition, for $24 \mathrm{~h}$. Optical images were acquired by using an inverted microscope (Olympus X71, Olympus, Tokyo, Japan). Meanwhile, the subdivided matrix glue was placed in a refrigerator at $4{ }^{\circ} \mathrm{C}$ overnight and then placed on the upper compartment surface of the membrane at the bottom of the transwell compartment, and then left stationary at room temperature for $3 \mathrm{~h}$. After discarding the remaining solution, $100 \mu \mathrm{L}$ of Opti-MEM was added to each well, and placed in an incubator for $30 \mathrm{~min}$. The cells were resuspended in Opti-MEM and the cell density was adjusted to $5 \times 10^{5}$ cells $/ \mathrm{mL}$. Then $200 \mu \mathrm{L}$ of cell suspension was added to the transwell chamber and $600 \mu \mathrm{L}$ DMEM was added to the 24-well culture plate chamber. The culture plates were placed in a $\mathrm{CO}_{2}$ incubator at $37^{\circ} \mathrm{C}$ for $24 \mathrm{~h}$. Finally, the samples were collected, washed twice with PBS, fixed with $4 \%$ paraformaldehyde for $20 \mathrm{~min}$, and stained with crystal violet for $20 \mathrm{~min}$. The images were acquired under the microscope and analyzed by imageJ software.

\section{Real-time quantitative PCR}

HepG2 and A549 cells were used to analyze the silencing activity of EAASc/siRNA under NG or SMG conditions. Cells were seeded in $25-\mathrm{cm}^{2}$ flask $24 \mathrm{~h}$ before transfection. EAASc/siRNA was transfected according to the above-mentioned protocol, followed by incubating for another $24 \mathrm{~h}$. Then total RNA was extracted using Trizol reagent (Invitrogen) according to standard manufacturer's instructions. One microgram of total RNA was transcribed to cDNA in a $20 \mu \mathrm{L}$ reaction mix. Then the mix was diluted to $100 \mu \mathrm{L}$ with $\mathrm{ddH}_{2} \mathrm{O}$, and $5 \mu \mathrm{L}$ of cDNA solution and SYBR Green PCR Master Mix were used to perform real-time quantitative PCR. Expression levels of PLK1 mRNA were determined by the $\mathrm{Ct}$ values according to a standard protocol.

In addition, mRNA expressions of the pivotal genes involved in RNAi pathway, including Argonaute 2 (Ago2), Dicer, heat shock protein 90 (Hsp90), transactivation response RNA binding protein (TRBP) and protein kinase RNA activator (PACT), were further determined by PCR to evaluate the effect of SMG on the expression of these genes. The cells were also seeded in $25-\mathrm{cm}^{2}$ flask and incubated under NG or SMG condition for $24 \mathrm{~h}$. The same protocol was used to conduct PCR detection, and glyceraldehyde-3-phosphate dehydrogenase (GAPDH) was used as the reference gene. All primers used in this study were shown in supplementary Table S2.

\section{Statistical analysis}

Statistical analysis was performed with GraphPad Prism 8.0 software. Data were presented as mean \pm SEM. The student's $t$ test and one-way ANOVA were used for multiple comparisons. Statistical differences were defined as ${ }^{*} p<0.05,{ }^{* *} p<0.01,{ }^{* * *} p<0.001$, and differences with $p<0.05$ were considered significant.

Acknowledgements This work was supported by the Hunan Provincial Natural Science Foundation of China (2018JJ1019, 2019JJ50196), the Hu-Xiang Young Talent Program (2018RS3094), The National Natural Science Foundation of China (31871003, 31901053), The Beijing Institute of Technology Research Fund Program for Young Scholars, and the Fundamental Research Funds for the Central Universities (3052018065).

\section{Compliance with Ethical Standards}

Conflict of interest Tongren Yang, Chanchan Yu, Changrong Wang, Chunhui Li, Mengjie Zhang, Xiaofan Luo, Yuhua Weng, Anjie Dong, Xiaoqiong Li, Yulin Deng, and Yuanyu Huang declare that they have no conflicts of interest.

Human and animal rights and informed consent This article does not contain any studies with human or animal subjects performed by any of the authors.

Open Access This article is licensed under a Creative Commons Attribution 4.0 International License, which permits use, sharing, adaptation, distribution and reproduction in any medium or format, as long as you give appropriate credit to the original author(s) and the source, provide a link to the Creative Commons licence, and indicate if changes were made. The images or other third party material in this article are included in the article's Creative Commons licence, unless indicated otherwise in a credit line to the material. If material is not included in the article's Creative Commons licence and your intended use is not permitted 
by statutory regulation or exceeds the permitted use, you will need to obtain permission directly from the copyright holder. To view a copy of this licence, visit http://creativecommons.org/ licenses/by/4.0/.

\section{References}

Ahn CB, Lee JH, Han DG, Kang HW, Lee SH, Lee JI, Son KH, Lee JW (2019) Simulated microgravity with floating environment promotes migration of non-small cell lung cancers. Sci Rep 9(1):14553

Bauer J, Wehland M, Infanger M, Grimm D, Gombocz E (2018) Semantic analysis of posttranslational modification of proteins accumulated in thyroid cancer cells exposed to simulated microgravity. Int J Mol Sci 19(8):2257

Braddock M (2020) From target identification to drug development in space: using the microgravity assist. Curr Drug Discov Technol 17(1):45-56

Clement G, Pavy-Le Traon A (2004) Centrifugation as a countermeasure during actual and simulated microgravity: a review. Eur J Appl Physiol 92(3):235-248

Crawford-Young SJ (2006) Effects of microgravity on cell cytoskeleton and embryogenesis. Int $\mathrm{J}$ Dev Biol 50(2-3):183-191

de Fougerolles A, Vornlocher HP, Maraganore J, Lieberman J (2007) Interfering with disease: a progress report on siRNAbased therapeutics. Nat Rev Drug Discov 6(6):443-453

Diab A, Foca A, Fusil F, Lahlali T, Jalaguier P, Amirache F, N'Guyen L, Isorce N, Cosset FL, Zoulim F, Andrisani O, Durantel D (2017) Polo-like-kinase 1 is a proviral host factor for hepatitis $\mathrm{B}$ virus replication. Hepatology 66(6):1750-1765

Du L, Wang C, Meng L, Cheng Q Zhou J, Wang X, Zhao D, Zhang J, Deng L, Liang Z, Dong A, Cao H (2018) The study of relationships between $\mathrm{pKa}$ value and siRNA delivery efficiency based on tri-block copolymers. Biomaterials 176:84-93

Egorov AD (1996) Qualification of human body reactions to microgravity. Aviakosm Ekolog Med 30(4):14-20

El Dika I, Lim HY, Yong WP, Lin CC, Yoon JH, Modiano M, Freilich B, Choi HJ, Chao TY, Kelley RK, Brown J, Knox J, Ryoo BY, Yau T, Abou-Alfa GK (2019) An open-label, multicenter, Phase I, dose escalation study with Phase II expansion cohort to determine the safety, pharmacokinetics, and preliminary antitumor activity of intravenous TKM-080301 in subjects with advanced hepatocellular carcinoma. Oncologist 24(6):747-e218

Eyal S, Derendorf H (2019) Medications in space. In Search of a Pharmacologist's Guide to the Galaxy. Pharm Res 36(10):148. https://doi.org/10.1007/s11095-019-2679-3

Foca A, Dhillon A, Lahlali T, Lucifora J, Salvetti A, Rivoire M, Lee A, Durantel D (2020) Antiviral activity of PLK1-targeting siRNA delivered by lipid nanoparticles in HBV-infected hepatocytes. Antivir Ther. https://doi.org/10.3851/imp3361

Gonzalez-Aseguinolaza G (2020) Givosiran-running RNA interference to fight porphyria attacks. $N$ Engl J Med 382(24):2366-2367

Grimm D, Bauer J, Kossmehl P, Shakibaei M, Schoberger J, Pickenhahn H, Schulze-Tanzil G, Vetter R, Eilles C, Paul M, Cogoli A (2002) Simulated microgravity alters differentiation and increases apoptosis in human follicular thyroid carcinoma cells. FASEB J 16(6):604-606

Hoy SM (2018) Patisiran: first global approval. Drugs 78(15):1625-1631
Hu B, Weng Y, Xia XH, Liang XJ, Huang Y (2019) Clinical advances of siRNA therapeutics. J Gene Med 21(7):e3097. https://doi. org/10.1002/jgm.3097

Hu B, Zhong L, Weng Y, Peng L, Huang Y, Zhao Y, Liang XJ (2020) Therapeutic siRNA: state of the art. Signal Transduct Target Ther 5(1):101. https://doi.org/10.1038/s41392-020-0207-x

Huang YY (2019) Approval of the first-ever RNAi therapeutics and its technological development history. Prog Biochem Biophys 46(3):313-322

Jhala DV, Kale RK, Singh RP (2014) Microgravity alters cancer growth and progression. Curr Cancer Drug Targets 14(4):394-406

Kong Y, Liu H, Li W, Wang D (2019) Intestine-specific activity of insulin signaling pathway in response to microgravity stress in Caenorhabditis elegans. Biochem Biophys Res Commun 517(2):278-284

Li J, Zhang S, Chen J, Du T, Wang Y, Wang Z (2009) Modeled microgravity causes changes in the cytoskeleton and focal adhesions, and decreases in migration in malignant human MCF-7 cells. Protoplasma 238(1-4):23-33

Li Y, Gao X, Ling S, Zhong G, Sun W, Liu C, Li J, Song J, Zhao D, Jin X, Li Y, Sun X-Q (2020) Knockdown of CD44 inhibits the alteration of osteoclast function induced by simulated microgravity. Acta Astronaut 166:607-612

Liu Z, Sun Q, Wang X (2017) PLK1, a potential target for cancer therapy. Transl Oncol 10(1):22-32

Loomer PM (2001) The impact of microgravity on bone metabolism in vitro and in vivo. Crit Rev Oral Biol Med 12(3):252-261

Masiello MG, Cucina A, Proietti S, Palombo A, Coluccia P, D’Anselmi F, Dinicola S, Pasqualato A, Morini V, Bizzarri M (2014) Phenotypic switch induced by simulated microgravity on MDA-MB-231 breast cancer cells. Biomed Res Int 2014:652434. https://doi.org/10.1155/2014/652434

Norsk P (2020) Adaptation of the cardiovascular system to weightlessness: surprises, paradoxes and implications for deep space missions. Acta Physiol (Oxf) 228(3):e13434. https://doi.org/10.1111/apha.13434

Ohta H, Baba A, Gabriel K (2002) Review of existing research on microgravity boiling and two-phase flow: future experiments on the international space station. Ann N Y Acad Sci 974:410-427

Paulsen K, Tauber S, Dumrese C, Bradacs G, Simmet DM, Golz N, Hauschild S, Raig C, Engeli S, Gutewort A, Hurlimann E, Biskup J, Unverdorben F, Rieder G, Hofmanner D, Mutschler L, Krammer S, Buttron I, Philpot C, Huge A, Lier H, Barz I, Engelmann F, Layer LE, Thiel CS, Ullrich O (2015) Regulation of ICAM-1 in cells of the monocyte/macrophage system in microgravity. Biomed Res Int 2015:538786

Reichert P, Prosise W, Fischmann TO, Scapin G, Narasimhan C, Spinale A, Polniak R, Yang X, Walsh E, Patel D, Benjamin W, Welch J, Simmons D, Strickland C (2019) Pembrolizumab microgravity crystallization experimentation. NPJ Microgravity $5: 28$

Roberts DR, Asemani D, Nietert PJ, Eckert MA, Inglesby DC, Bloomberg JJ, George MS, Brown TR (2019) Prolonged microgravity affects human brain structure and function. AJNR Am J Neuroradiol 40(11):1878-1885

Scott LJ (2020) Givosiran: first approval. Drugs 80(3):335-339

Shi W, Xie Y, He J, Zhou J, Gao Y, Wei W, Ding N, Ma H, Xian CJ, Chen K, Wang J (2017) Microgravity induces inhibition of osteoblastic differentiation and mineralization through abrogating primary cilia. Sci Rep 7(1):1866. https://doi.org/10. 1038/s41598-017-02049-9

Shi W, Zhang Y, Chen K, He J, Feng X, Wei W, Hua J, Wang J (2020) Primary cilia act as microgravity sensors by depolymerizing 
microtubules to inhibit osteoblastic differentiation and mineralization. Bone 136:115346. https://doi.org/10.1016/j. bone.2020.115346

Strube F, Infanger M, Wehland M, Delvinioti X, Romswinkel A, Dietz C, Kraus A (2020) Alteration of cytoskeleton morphology and gene expression in human breast cancer cells under simulated microgravity. Cell J 22(1):106-114

Uchida T, Sakashita Y, Kitahata K, Yamashita Y, Tomida C, Kimori Y, Komatsu A, Hirasaka K, Ohno A, Nakao R, Higashitani A, Higashibata A, Ishioka N, Shimazu T, Kobayashi T, Okumura Y, Choi I, Oarada M, Mills EM, Teshima-Kondo S, Takeda S, Tanaka E, Tanaka K, Sokabe M, Nikawa T (2018) Reactive oxygen species upregulate expression of muscle atrophyassociated ubiquitin ligase Cbl-b in rat L6 skeletal muscle cells. Am J Physiol Cell Physiol 314(6):C721-C731

Wang H, Sun Z, Wang Y, Hu Z, Zhou H, Zhang L, Hong B, Zhang S, Cao X (2016) miR-33-5p, a novel mechano-sensitive microRNA promotes osteoblast differentiation by targeting Hmga2. Sci Rep 6:23170. https://doi.org/10.1038/srep23170

Weng Y, Xiao H, Zhang J, Liang XJ, Huang Y (2019) RNAi therapeutic and its innovative biotechnological evolution. Biotechnol Adv 37(5):801-825

Whitehead KA, Dorkin JR, Vegas AJ, Chang PH, Veiseh O, Matthews J, Fenton OS, Zhang Y, Olejnik KT, Yesilyurt V, Chen D, Barros S,
Klebanov B, Novobrantseva T, Langer R, Anderson DG (2014) Degradable lipid nanoparticles with predictable in vivo siRNA delivery activity. Nat Commun 5:4277. https://doi.org/10. 1038/ncomms5277

Wostyn P, Mader TH, Gibson CR, Killer HE (2019) The escape of retrobulbar cerebrospinal fluid in the astronaut's eye: mission impossible? Eye (Lond) 33(10):1519-1524

Wu C, Wang W, Fang L, Su W (2018) Programmable pyrroleimidazole polyamides: a potent tool for DNA targeting. Chin Chem Lett 29(7):1105-1112

Zhang M, Weng Y, Cao Z, Guo S, Hu B, Lu M, Guo W, Yang T, Li C, Yang X, Huang Y (2020) ROS-Activatable siRNA-engineered polyplex for NIR-triggered synergistic cancer treatment. ACS Appl Mater Interfaces 12(29):32289-32300

Zhao D, Yang G, Liu Q, Liu W, Weng Y, Zhao Y, Qu F, Li L, Huang Y (2020) A photo-triggerable aptamer nanoswitch for spatiotemporal controllable siRNA delivery. Nanoscale 12(20):10939-10943

Zhou J, Wu Y, Wang C, Cheng Q, Han S, Wang X, Zhang J, Deng L, Zhao D, Du L, Cao H, Liang Z, Huang Y, Dong A (2016) pHSensitive nanomicelles for high-efficiency siRNA delivery in vitro and in vivo: an insight into the design of polycations with robust cytosolic release. Nano Lett 16(11):6916-6923 